\title{
New legume sources as therapeutic agents
}

\author{
Zecharia Madar* and Aliza H. Stark \\ The Hebrew University of Jerusalem, Faculty of Agricultural, Food and Environmental Quality Sciences, \\ Institute of Biochemistry, Food Science and Nutrition, P.O. Box 12, Rehovot 76100, Israel
}

\begin{abstract}
This review evaluates the potential health benefits of three legume sources that rarely appear in Western diets and are often overlooked as functional foods. Fenugreek (Trigonella foenum graecum) and isolated fenugreek fractions have been shown to act as hypoglycaemic and hypocholesterolaemic agents in both animal and human studies. The unique dietary fibre composition and high saponin content in fenugreek appears to be responsible for these therapeutic properties. Faba beans (Vicia faba) have lipid-lowering effects and may also be a good source of antioxidants and chemopreventive factors. Mung beans (Phaseolus aureus, Vigna radiatus ) are thought to be beneficial as an antidiabetic, low glycaemic index food, rich in antioxidants. Evidence suggests that these three novel sources of legumes may provide health benefits when included in the daily diet.
\end{abstract}

Legumes: Fenugreek: Faba beans: Mung beans

\section{Introduction}

It has long been recognized that legumes are functional foods that both promote good health and have therapeutic properties (Geil \& Anderson, 1994). Legumes are a good source of starch, dietary fibre, protein and minerals such as $\mathrm{Ca}, \mathrm{Fe}, \mathrm{K}, \mathrm{Mg}$ and $\mathrm{Zn}$. They are also low in $\mathrm{Na}$ and contain no cholesterol. As a group, the nutrient composition of legumes makes them ideal foods to meet dietary recommendations, but consumption in Western countries is low and few distinctions are made between the numerous varieties. In comparison to the more commonly eaten grain products, the health benefits of legumes have been somewhat overlooked. Legumes have low glycaemic indexes (Foster-Powell \& Miller, 1995), have been shown to have hypocholesterolaemic effects (Anderson et al. 1999) and contain phytochemicals that may act as chemopreventive agents. As data accumulate, it becomes increasingly clear that the physiological effects of different legumes vary significantly. These differences may result from polysaccharide composition, in particular quantity and variety of dietary fibre and starch, protein make-up, and variability in phytochemical content. Overall, with the exception of soyabeans, few nutritional studies have been carried out in the area of legumes, and even fewer have distinguished between the individual characteristics of this heterogeneous family of foods. Therefore, investigation of less commonly consumed legumes may reveal new sources of functional foods, as potent natural food sources that will prevent disease and act as therapeutic agents. The present paper will focus on three pulses that are common in Asia and Africa, but are less well known in Europe and North America.

\section{New legume sources \\ Fenugreek (Trigonella foenum graecum)}

Fenugreek, a legume grown in the Middle East and Asia, has been used for centuries in folk medicine to heal ailments ranging from indigestion to baldness. Studies indicate that fenugreek and isolated fenugreek fractions have numerous therapeutic properties. Fenugreek has repeatedly been shown to have potent antidiabetic activity (Ribes et al. 1986; Madar et al. 1988; Sharma \& Raghuram, 1990; Sharma et al. 1990; Khosla et al. 1995), the ability to lower plasma cholesterol levels (Sharma, 1984; Valette et al. 1984; Sharma, 1986; Sharma et al. 1990; Stark \& Madar, 1993; Rao, 1996), antioxidant activity (Ravikumar \& Anuradha, 1999) and possess antineoplastic and antiinflammatory properties (Sur et al. 2001). Equally important to its health promoting potential, there is no evidence that fenugreek produces any acute or cumulative toxicity (Rao, 1996; Muralidhara et al. 1999).

Fenugreek contains $23-26 \%$ protein, $6-7 \%$ fat and $58 \%$ carbohydrates of which $25 \%$ is dietary fibre (US

\footnotetext{
Abbreviations: EAC, Ehrlich ascites carcinoma; G, galactose; IDDM, insulin-dependent diabetes mellitus; M, mannose; NIDDM, non-insulin-dependent diabetes mellitus; 4-OH-Ile, 4-hydroxyisoleucine.

* Corresponding author: Professor Zecharia Madar, tel +972 8 9489008, fax +972 89363208 , email madar@agri.huji.ac.il
} 
Department of Agriculture, 2001). Measurements of up to $48 \%$ (w/w) of dietary fibre have been reported in fenugreek samples (Sharma, 1986). Fenugreek is also a rich source of $\mathrm{Fe}$, containing $33 \mathrm{mg} / 100 \mathrm{~g}$ dry weight (US Department of Agriculture, 2001). Similar to other legumes, fenugreek contains saponins, with estimates of up to $5 \% \mathrm{w} / \mathrm{w}$ saponins (Valette et al. 1984). Although some of the saponins in fenugreek have been identified (Price et al. 1987; Murakami et al. 2000), the structures of the saponins found in fenugreek are still being characterized.

The dietary fibre of fenugreek seeds is dispersed throughout the seed coat and is also found in the endosperm (Meier \& Reid, 1977). Chemical analysis of a water-soluble fraction of the seeds found high concentrations of galactomannans (Madar \& Shomer, 1990). The galactomannans are characterized by their high water-holding capacity (16-fold by weight) and by their ability to form highly viscous gels even when relatively diluted (Madar \& Shomer, 1990). Galactomannans are highly hydrophilic in nature and adsorb at interfaces and reduce surface and interfacial tension to levels whereby they can be categorized as surfactants (Garti et al. 1997).

Fenugreek gel consists predominately of galactomannans with a mannose $(\mathrm{M})$ backbone grafted with galactose (G) units on an average ratio of 1:1. The unique structure of the fenugreek galactomannans, different from those found in guar gum (1G:2M) or locust bean gum (1G:4M), may be responsible for the unique therapeutic properties attributed to fenugreek (Evans et al. 1992). Because of the 1:1 ratio, fenugreek gum is relatively rich in galactose and therefore, has particularly high water solubility.

The use of fenugreek has been limited due to its bitter taste and pungent odour. Work to isolate the biologically active components, or to produce a debittered product, has been carried out to allow greater use of this legume. The therapeutic properties of fenugreek have been investigated in whole fenugreek seeds, and in various isolates.

Antidiabetic activity. Studies carried out in human subjects show that fenugreek reduces the post-prandial glucose response in both healthy and diabetic individuals. Sharma (1986) observed in acute studies, that whole fenugreek seeds, a gum isolate and defatted seeds all reduced the area under the glucose curve by $35-42 \%$ and post-prandial insulin levels were also significantly reduced. In contrast, degummed seeds had little effect on the glycaemic response. Madar et al. (1988) reported similar results in non-insulin-dependent diabetics (NIDDM) when $15 \mathrm{~g}$ of ground fenugreek seeds were added to a meal tolerance test. These results were confirmed in longer metabolic studies of $10 \mathrm{~d}$ to 2 months in both NIDDM and insulindependent diabetic (IDDM) subjects consuming $100 \mathrm{~g} / \mathrm{d}$ of debittered fenugreek, or fenugreek extracts (Sharma \& Raghuram, 1990; Sharma et al. 1990; Gupta et al. 2001). Fenugreek has been shown to have a high efficacy at relatively low doses and during both acute and longer-term interventions.

Animal studies have been carried out to investigate the mechanisms by which fenugreek induces a hypoglycaemic effect. Studies in streptozotocin diabetic rats (model of
IDDM), using ground fenugreek seeds, showed that intubation in combination with a standard starch solution dramatically decreased post-prandial glucose tolerance curves and also significantly reduced the rate of gastric emptying (Madar, 1984). Inhibited glucose transport was also observed in vitro using inverted sections of rat intestines incubated with fenugreek (Madar, 1984). The highly viscous gel fraction of fenugreek, rich in galactomannans, was also an effective hypoglycaemic agent (Madar \& Shomer, 1990) and significantly inhibited glucose absorption from perfused loops of small intestine (Evans et al. 1992). It appears that the soluble dietary fibres in fenugreek acting in the intestinal tract are largely responsible for its strong hypoglycaemic action, and are biologically active in both ground whole seeds and as a purified isolate.

In order to market fenugreek successfully to the public, the soluble dietary fibre fraction rich in galactomannans has been isolated. This fraction is virtually odourless and tasteless, and can easily be incorporated into foodstuffs or taken in capsule form. Industry has successfully added fenugreek isolates to ice cream, pasta, breads and biscuits. When these products were tested in healthy individuals, the glycaemic response was markedly reduced. A $25-60 \%$ decrease in peak glucose levels was observed along with significant decreases in the area under the glucose curves. Addition of fenugreek gel was able to significantly reduce the glycaemic index of these food products (unpublished data).

Recently, Broca et al. (1999, 2000) have demonstrated that the amino acid, 4-hydroxyisoleucine (4-OH-Ile), found in fenugreek, has both insulinotropic and antidiabetic properties. This amino acid has only been isolated in plants, and is found in fenugreek seeds at concentrations of $0.56 \% \mathrm{w} / \mathrm{w}$. Intravenous and oral glucose tolerance tests were carried out in healthy dogs and rats and the addition of 4-OH-Ile improved glucose tolerance. Furthermore, a single administration of 4-OH-Ile to IDDM rats partially restored a glucose-induced insulin response. A $6 \mathrm{~d}$ subchronic administration of 4-OH-Ile reduced basal hyperglycaemia, decreased basal insulinaemia and tended to improve overall glucose tolerance. In vitro work by the same investigators indicated that 4-OH-Ile directly caused pancreatic $\beta$ cell stimulation. This stimulation was seen in the micromolar range, but only in the linear isoform of the amino acid (Broca et al. 2000). It appears that the protein fraction of fenugreek contains biologically active components that may be useful in both preventing and treating diabetes.

Effects on lipid metabolism. The ability of fenugreek to influence lipid metabolism is well established. Studies carried out in human subjects fed $100 \mathrm{~g}$ of defatted fenugreek powder for a $10 \mathrm{~d}$ period, resulted in decreased levels of serum total cholesterol, LDL- and VLDL-cholesterol and triglyceride levels without alteration of the HDLcholesterol levels (Sharma \& Raghuram, 1990). When germinated fenugreek seeds were added to the diet of hypocholesterolaemic subjects $(12.5$ or $18 \mathrm{~g} / \mathrm{d})$ for $30 \mathrm{~d}$, total cholesterol levels and LDL-cholesterol levels were significantly reduced (Sowmya \& Rajyalakshmi, 1999). In type 2 diabetics, $1 \mathrm{~g} / \mathrm{d}$ of a hydroalcoholic extract added to the daily diet for a 2-month period significantly decreased serum triglycerides and increased HDL-cholesterol (Gupta et al. 2001). 
Results from animal studies help to elucidate potential mechanisms by which fenugreek and fenugreek fractions act as hypocholesterolaemic agents. Sharma (1984) proposed that ground fenugreek seeds, added to a hypercholesterolaemia-inducing diet in rats, prevented elevation of plasma cholesterol levels by increasing faecal bile acid and cholesterol excretion. When various fenugreek fractions were tested, it was shown that neither the lipid extract nor isolated trigonelline were responsible for this property (Sharma, 1986). Defatted seeds, a gum isolate (rich in dietary fibres) and a crude saponin extract all retained the hypocholesterolaemic characteristics of the whole fenugreek seeds. Stark \& Madar (1993), using an ethanol extract from ground fenugreek seeds, found that the saponin-rich isolate lowered plasma cholesterol levels in hypercholesterolaemic rats by $18-26 \%$. The ethanol extract inhibited bile acid absorption in inverted segments of rat intestine in a dose-dependent manner. This suggests that an interaction may be occurring in the digestive tract between bile acids and saponins. It has been hypothesized that micelles are formed from bile acids and saponins, which are not available for absorption due to their large size. This mechanism has been proposed for other saponincontaining foods, such as soya, which also have hypocholesterolaemic properties (Sidhu \& Oakenfull, 1986).

The work of Evans et al. (1992) suggests that the gum fraction or dietary fibre fraction of the fenugreek seed is responsible for its ability to lower cholesterol levels. Using a hypercholesterolaemia-inducing diet in rats, it was observed that feeding galactomannans from fenugreek lowered both liver and plasma cholesterol levels and that the rate of hepatic synthesis of cholesterol was decreased. It is quite possible that both the dietary fibre and saponinrich fraction contribute to the cholesterol-lowering capabilities of whole fenugreek seeds.

Additional therapeutic properties. The effect of fenugreek seeds on blood lipid peroxidation and antioxidants was investigated in diabetic rats (Ravikumar \& Anuradha, 1999). Alloxan-induced diabetes in rats led to increased lipid peroxidation and alterations in circulating antioxidants. Supplementation with fenugreek seeds in these rats significantly lowered lipid peroxidation. In addition, glutathione and $\beta$-carotene contents were increased but $\alpha$-tocopherol levels were lowered. The study showed that the disrupted free-radical metabolism in diabetic rats may be normalized by consumption of fenugreek.

The antineoplastic effect of Trigonella foenum graecum seed extract has been evaluated in the Ehrlich ascites carcinoma (EAC) model in Balb-C mice. Intraperitoneal administration of an alcohol extract of fenugreek both before and after inoculation of EAC cells in mice produced more than $70 \%$ inhibition of tumour cell growth with respect to the control. Treatment with the extract was found to enhance both the peritoneal exudate cell and macrophage cell counts. The extract also produced a significant anti-inflammatory effect (Sur et al. 2001).

\section{Faba bean (Vicia faba)}

The faba bean is one of the world's oldest crops and its economic importance is considerable. Two types of faba beans are eaten, one with an average weight of $800 \mathrm{mg}$ ( $V$. faba major or broad bean) and the other weighing approximately $550 \mathrm{mg}$ ( $V$. faba minor, horse bean, tick bean). Faba beans are commonly eaten in the Mediterranean, China and Brazil. The nutrient composition of faba beans is $26 \%$ protein, $1-2 \%$ fat, $58 \%$ carbohydrates and $25 \%$ dietary fibre (US Department of Agriculture, 2001). There is a significant negative correlation between the in vitro digestibility of faba bean protein and tannin content of the seed. The tannins are found in the hulls, and dehulling is reported to increase the protein digestibility by $85-90 \%$. In contrast, the presence of other antinutritional factors, such as lectins and protease inhibitors, is low (Smartt, 1990). Faba beans have a relatively high glycaemic index when compared to other legumes being $79 \pm$ $16 \%$ of the glucose standard (Foster-Powell \& Miller, 1995).

Concern over a decrease in bioavailability of various minerals is associated with legume intake. This problem was investigated in a study carried out in rats which measured mineral balance following consumption of faba beans or faba bean fibre (insoluble residue from hulls) (Rubio et al. 1992). Whole faba beans significantly reduced the apparent absorption of both $\mathrm{Zn}$ and $\mathrm{Mn}$; however, the consumption of the hulls led to reduced $\mathrm{Fe}$ absorption, while $\mathrm{Cu}$ absorption was slightly increased. The faba bean varieties used in this particular study had relatively low phytate content; it is quite likely that a higher phytate content would further impair mineral balance.

Faba bean consumption is limited in some populations due to favism, haemolytic anaemia due to a congenital deficiency of the enzyme glucose-6-phosphate dehydrogenase (Smartt, 1990). Therefore, before making general recommendations for increasing faba bean consumption in a particular population, mineral status and the prevalence of favism should be considered.

Effects on lipid metabolism. Faba beans are thought to have a beneficial impact on lipid profiles. In human studies, Weck et al. (1983) demonstrated that in subjects with hypercholesterolaemia (type IIa), faba bean protein had a cholesterol-reducing efficacy comparable to that of soya protein. The lipid-lowering effects of Vicia faba have been documented more extensively in animal studies. When faba beans were added to a hypercholesterolaemiainducing diet fed to rats, a significant decrease in plasma cholesterol levels was observed after 2 weeks of intervention (Bonilla et al. 1998). Macarulla et al. (2001) also reported that both whole seeds and a protein isolate fed to rats significantly decreased plasma LDL + VLDLcholesterol while HDL-cholesterol levels were unchanged. Hepatic cholesterol and triacylglycerol were also reduced. The whole seeds had the added benefit of lowering plasma triacylglycerol levels. When the hypocholesterolaemic mechanisms were investigated, endogenous cholesterol synthesis was not reduced, but increased faecal steroid excretion was observed. Because the whole seed was more effective than the protein isolate, it may be concluded that other components of the faba bean (i.e. dietary fibre) contribute to its hypocholesterolaemic properties.

Additional therapeutic properties. Faba beans contain agglutinin, a lectin that has been shown to alter the 
proliferation rate of colonic cells (Jordinson et al. 1999). In a human colon cancer cell line, lectins from faba beans were able to stimulate undifferentiated cells to form gland-like structures. Cellular differentiation of this variety is thought to slow the progression of colon cancer and inhibit uncontrolled cellular proliferation. Although lectins are commonly considered to be antinutritional factors, their adverse effects are diminished following denaturation during cooking. It is unclear if thermal treatment of the lectins used in these experiments would modify experimental results.

Water-soluble proteins were isolated from faba beans and their ability to act as free-radical scavengers was investigated in a human fibroblast model (Okada \& Okada, 2000). In this model, the proteins from faba beans induced an increase in catalase activity and glutathione concentrations, which suggest an enhanced antioxidative capacity in tissues exposed to the faba bean protein isolate. The effects of thermal treatment on these proteins were not reported.

\section{Mung beans (Phaseolus aureus, Vigna radiatus)}

The mung bean is an ancient crop of Asia, where there are many seed sizes, shapes and colours. Mung beans, or green gram, are similar in composition to other members of the legume family, with $24 \%$ protein, $1 \%$ fat, $63 \%$ carbohydrate and $16 \%$ dietary fibre (US Department of Agriculture, 2001). Similar to most legumes, mung beans lack sulphur-containing amino acids and uncooked beans contain trypsin inhibitors (Khader \& Rao, 1996). Cooking slightly improves the nutritive value. Mung beans are commonly eaten as bean sprouts, and extruded mung bean starch is used in the production of vermicelli or glass noodles. These noodles are made from a mixture of mung bean starch and potato starch and, when boiled, become gelatinous in texture and transparent.

Antidiabetic activity. Mung bean starch is considered to be a low glycaemic index carbohydrate (Juliano et al. 1989; Lerer-Metzger et al. 1996; Kabir et al. 1998, 2000). When tested in non-insulin-dependent diabetics, cooked noodles from mung beans were shown to have a lower glycaemic index than two types of cooked rice and five other types of noodles (Juliano et al. 1989). In addition, in vitro starch digestibility was low and amylose content was high. An additional study indicated that the mung bean starch contained approximately $8 \%$ resistant starch (Lerer-Metzger et al. 1996). It is likely that both the high amylose content and the presence of resistant starch formed from retrogradation in thermal processing contribute to the low glycaemic index of mung bean products.

In healthy rats, feeding of mung bean starch for 5 weeks led to lowered non-fasting plasma glucose and free fatty acid levels in comparison to rats fed wheat starch. In both healthy and diabetic rats the mung bean starch reduced plasma triacylglycerol concentrations and adipocyte volume was decreased. This indicates that the use of starch from mung beans may be beneficial for modifying both glucose and lipid metabolism. Kabir et al. (1998) showed that in comparison to a high glycaemic index starch (waxy cornstarch), the use of mung bean starch from cooked and powdered Chinese noodles led to lower fatty acid synthase activity and mRNA expression in adipose tissue but not in liver of healthy rats. Furthermore, Glut4 expression was lower in adipose tissue, suggesting that less glucose is available for lipogenesis. In an additional study by the same group of investigators (Kabir et al. 2000), long-term feeding (12 weeks) of mung bean starch in rats resulted in significantly higher levels of plasma leptin and lower levels of circulating free fatty acids. These results indicate that consumption of starch from a legume source influences plasma leptin levels and may have a beneficial effect in preventing weight gain or increasing fat mass.

Effects on lipid metabolism. Dietary fibre prepared from crude mung bean sprouts (Nishimura et al. 2000) was tested for its cholesterol-lowering effects in rats. Following $21 \mathrm{~d}$ on a fibre-enriched diet, a significant reduction in total plasma cholesterol levels was observed, accompanied by an increase in total caecal short-chain fatty acids. These data confirm that mung bean sprouts contain fermentable dietary fibres, but the role of caecal fermentation products in lipid metabolism remains to be elucidated.

Additional therapeutic properties. A methanol extract of mung bean hulls was shown to have a wide range of in vitro antioxidative properties (Duh et al. 1999). Lipid and protein oxidation were inhibited along with decreased deoxyribose damage. The extract exhibited metal-binding ability and free-radical scavenging activity, both potential mechanisms by which lipids and non-lipids are protected from oxidative damage. Lee et al. $(2000 a, b)$ demonstrated that an aroma extract from mung beans produced by steam distillation possessed antioxidative activity which was comparable to that of vitamin E. Maltol and eugenol were identified, both considered potent antioxidants.

\section{Conclusions}

Research to substantiate the therapeutic properties of novel legume sources is limited and an insufficient number of controlled studies have been carried out to confirm health benefits definitively. However, based on the available data, it appears that novel sources of legumes have a wide variety of health-promoting activities. In addition, it should be noted that no two legumes are the same, and that some varieties have greater potential to act as therapeutic agents than others. It is important to increase awareness of the public, researchers, doctors and nutritionists as to the unique properties of individual legumes in order to recommend those that are most beneficial for maintaining good health and preventing disease. It is also important to investigate legumes that are less well-known but which may have potential as functional foods.

\section{References}

Anderson JW, Smith BM \& Washnock CS (1999) Cardiovascular and renal benefits of dry bean and soybean intake. American Journal of Clinical Nutrition 70, 464S-474S. 
Bonilla S, Noel-Suberville C, Higueret P, Puy Portillo M, Macarulla MT, Martinez A \& Garcin H (1998) Inclusion of a legume in a saturated fat-rich diet affects the cholesterol status but not the expression of triiodothyronine and retinoic acid receptors in rat liver. Annals of Nutrition and Metabolism 42, 297-303.

Broca C, Gross R, Petit P, Sauvaire Y, Manteghetti M, Tournier M, Masiello P, Gomis R \& Ribes G (1999) 4-Hydroxyisoleucine: experimental evidence of its insulinotropic and antidiabetic properties. American Journal of Physiology 277, E617-E623.

Broca C, Manteghetti M, Gross R, Baissac Y, Jacob M, Petit P, Sauvaire Y \& Ribes G (2000) 4-Hydroxyisoleucine: effects of synthetic and natural analogues on insulin secretion. European Journal of Pharmocology 390, 339-345.

Duh PD, Du PC \& Yen GC (1999) Action of methanolic extract of mung bean hulls as inhibitors of lipid peroxidation and nonlipid oxidative damage. Food Chemistry and Toxicology 37, 1055-1061.

Evans AJ, Hood RL, Oakenfull DG \& Sidhu GS (1992) Relationship between structure and function of dietary fibre: a comparative study of the effects of three galactomannans on cholesterol metabolism in the rat. British Journal of Nutrition 68, 217-229.

Foster-Powell K \& Miller JB (1995) International tables of glycemic index. American Journal of Clinical Nutrition 62, $871 \mathrm{~S}-890 \mathrm{~S}$.

Garti N, Aserin A, Sternheim B \& Madar Z (1997) Fenugreek galactomannans as food emulsifiers. Food Science and Technology 30, 305-311.

Geil PB \& Anderson JW (1994) Nutrition and health implications of dry beans: a review. Journal of the American College of Nutrition 13, 549-558.

Gupta A, Gupta R \& Lai B (2001) Effect of Trigonella foenumgraecum (fenugreek) seeds on glycaemic control and insulin resistance in type 2 diabetes mellitus: a double blind placebo controlled study. Journal of the Association of Physicians of India 49, 1057-1061.

Jordinson M, El-Hariry I, Calnan D, Calam J \& Pignatelli M (1999) Vicia faba agglutinin, the lectin present in broad beans, stimulates differentiation of undifferentiated colon cancer cells. Gut 44, 709-714.

Juliano BO, Perez CM, Komindr S \& Banphotkasem S (1989) Properties of Thai cooked rice and noodles differing in glycemic index in noninsulin-dependent diabetics. Plant Foods for Human Nutrition 39, 369-374.

Kabir M, Guerre-Millo M, Laromiguiere M, Slama G \& Rizkalla SW (2000) Negative regulation of leptin by chronic highglycemic index starch diet. Metabolism 49, 764-769.

Kabir M, Rizkalla SW, Quignard-Boulange A, Guerre-Millo M, Boillot J, Ardouin B, Luo J \& Slama G (1998) A high glycemic index starch diet affects lipid storage-related enzymes in normal and to a lesser extent in diabetic rats. Journal of Nutrition 128, 1878-1883.

Khader V \& Rao SV (1996) Studies on protein quality of green gram (Phaseolus aureus). Plant Foods for Human Nutrition 49, 127-132.

Khosla P, Gupta DD \& Nagpal RK (1995) Effect of Trigonella foenum graecum (Fenugreek) on blood glucose in normal and diabetic rats. Indian Journal of Physiology and Pharmacology 39, $173-174$.

Lee KG, Mitchell A \& Shibamoto T (2000a) Antioxidative activities of aroma extracts isolated from natural plants. Biofactors 13, $173-178$.

Lee KG, Mitchell AE \& Shibamoto T (2000b) Determination of antioxidant properties of aroma extracts from various beans. Journal of Agricultural and Food Chemistry 48, 4817-4820.

Lerer-Metzger M, Rizkalla SW, Luo J, Champ M, Kabir M,
Bruzzo F, Bornet F \& Slama G (1996) Effects of long-term low-glycaemic index starchy food on plasma glucose and lipid concentrations and adipose tissue cellularity in normal and diabetic rats. British Journal of Nutrition 75, 723-732.

Macarulla MT, Medina C, De Diego MA, Chavarri M, Zulet MA, Martinez JA, Noel-Suberville C, Higueret P \& Portillo MP (2001) Effects of the whole seed and a protein isolate of faba bean (Vicia faba) on the cholesterol metabolism of hypercholesterolaemic rats. British Journal of Nutrition 85, 607-614.

Madar Z (1984) Fenugreek (Trigonella foenum graecum) as a means of reducing postprandial glucose level in diabetic rats. Nutrition Reports International 29, 1267-1273.

Madar Z, Abel R, Samish S \& Arad J (1988) Glucose-lowering effect of fenugreek in non-insulin dependent diabetics. European Journal of Clinical Nutrition 42, 51-54.

Madar Z \& Shomer I (1990) Polysaccharide composition of a gel fraction derived from fenugreek and its effect on starch digestion and bile acid absorption in rats. Journal of Agriculture and Food Chemistry 38, 1535-1539.

Meier H \& Reid JSG (1977) Morphological aspects of the galactomannan formation in the endosperm of Trigonella foenum graecum L. (leguminosae). Planta 133, 243-248.

Murakami T, Kishi A, Matsuda H \& Yoshikawa M (2000) Medicinal foodstuffs. XVII. Fenugreek seed. (3): structures of new furostanol-type steroid saponins, trigoneosides $\mathrm{Xa}, \mathrm{Xb}, \mathrm{XIb}$, XIIa, XIIb, and XIIIa, from the seeds of Egyptian Trigonella foenum-graecum L. Chemical and Pharmaceutical Bulletin (Tokyo) 48, 994-1000.

Muralidhara, Narasimhamurthy K, Viswanatha S \& Ramesh BS (1999) Acute and subchronic toxicity assessment of debitterized fenugreek powder in the mouse and rat. Food Chemistry and Toxicology 37, 831-838.

Nishimura N, Taniguchi Y \& Kiriyama S (2000) Plasma cholesterol-lowering effect on rats of dietary fiber extracted from immature plants. Bioscience, Biotechnology, and Biochemistry 64, 2543-2551.

Okada Y \& Okada M (2000) Effect of a radical scavenger "water soluble protein' from broad beans (Vicia faba) on antioxidative enzyme activity in cellular aging. Journal of Nutrition Science Vitaminology (Tokyo) 46, 1-6.

Price KR, Johnson IT \& Fenwick GR (1987) The Chemistry and Biological Significance of Saponins in Foods and Feedingstuffs, pp. 46-47. CRC Critical Reviews in Food Science and Nutrition. Boca Raton, FL: CRC Press.

Rao PU (1996) Nutrient composition and biological evaluation of mesta (Hibiscus sabdariffa) seeds. Plant Foods for Human Nutrition 49, 27-34.

Ravikumar P \& Anuradha CV (1999) Effect of fenugreek seeds on blood lipid peroxidation and antioxidants in diabetic rats. Phytotherapy Research 13, 197-201.

Ribes G, Sauvaire Y, Da Costa C, Baccou JC \& LoubatieresMariani MM (1986) Antidiabetic effects of subfractions from fenugreek seeds in diabetic dogs. Proceedings of the Society of Experimental Biology and Medicine 182, 159-166.

Rubio LA, Grant G, Bardocz S, Dewey P \& Pusztai A (1992) Mineral excretion of rats fed on diets containing faba beans (Vicia faba L.) or faba bean fractions. British Journal of Nutrition 67, 295-302.

Sharma RD (1984) Hypocholesterolemic activity of fenugreek ( $T$. foenum graecum). An experimental study in rats. Nutrition Reports International 30, 221-231.

Sharma RD (1986) An evaluation of hypocholesterolemic factor of fenugreek seeds ( $T$. foenum graecum) in rats. Nutrition Reports International 33, 669-677.

Sharma RD \& Raghuram TC (1990) Hypoglycaemic effect of 
fenugreek seeds in non-insulin dependent diabetic subjects. Nutrition Research 10, 731-739.

Sharma RD, Raghuram TC \& Rao NS (1990) Effect of fenugreek seeds on blood glucose and serum lipids in type I diabetes. European Journal of Clinical Nutrition 44, 301-306.

Sidhu GS \& Oakenfull DG (1986) A mechanism for the hypocholesterolaemic activity of saponins. British Journal of Nutrition 55, 643-649.

Smartt J (1990) Grain Legumes: Evolution and Genetic Resources, pp. 198-206. Cambridge: Cambridge University Press.

Sowmya P \& Rajyalakshmi P (1999) Hypocholesterolemic effect of germinated fenugreek seeds in human subjects. Plant Foods for Human Nutrition 53, 359-365.

Stark A \& Madar Z (1993) The effect of an ethanol extract derived from fenugreek (Trigonella foenum-graecum) on bile acid absorption and cholesterol levels in rats. British Journal of Nutrition 69, 277-287.

Sur P, Das M, Gomes A, Vedasiromoni JR, Sahu NP, Banerjee S, Sharma RM \& Ganguly DK (2001) Trigonella foenum graecum (fenugreek) seed extract as an antineoplastic agent. Phytotherapy Research 15, 257-259.

US Department of Agriculture (2001) Nutrient Database for Standard Reference. Release 14. Washington DC: US Department of Agriculture.

Valette G, Sauvaire Y, Baccou JC \& Ribes G (1984) Hypocholesterolaemic effect of fenugreek seeds in dogs. Atherosclerosis 50, 105-111.

Weck M, Hanefeld M, Leonhardt W, Haller H, Robowsky KD, Noack R \& Schmandke H (1983) (Field bean protein diet in hypercholesterolemia). Nahrung 27, 327-333. 